\title{
The Training of Academic Librar Staff on Information Technology within the Libraries of the Minnesota State Colleges and Universities System
}

\author{
Teresa E. Kirkpatrick
}

\begin{abstract}
There is much discussion in the literature of library and information science on the need for training, and it is generally recognized that libraries do not devote as much time and energy to training their staff as they should. However, the surveys of training practice that are common in the private sector seldom are done in the library world. The purpose of this study was to survey academic libraries within the Minnesota State Colleges and Universities (MnSCU) system to find out what the current training practices are within these libraries. Seventeen out of twentythree libraries responded to a survey that attempted to determine (1) the types of technologies on which staff receive training, (2) the methods being used to train staff on technology, and (3) whether any differences exist in the training that professional and paraprofessional staff receive.
\end{abstract}

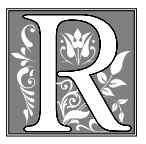

oy Tennant has addressed staff training as a "foundation" of the much-heralded virtual library, where technology is used extensively to provide access beyond the walls of the library. ${ }^{1}$ But whether the subject is the library of the future or the library of the present, Tennant is not alone in his assertion that staff training is important. It is widely recognized in the literature of library and information science that there is a need for library staff who are well trained in information technology. Moreover, it is recognized that the training of library staff might not be occurring as much as it should.

Sheila D. Creth suggested that a performance evaluation of staff development be conducted so that the extent to which a gap exists between what libraries are doing and what they should be doing will be known. ${ }^{2}$ Creth stated that even with all the programs, workshops, and increased publications on staff development-which would suggest that as a profession we are improving in our general understanding, commitment, and action in addressing the needs of all li-

Teresa E. Kirkpatrick is the Staff Development/Public Relations Librarian at Indiana State University; e-mail: libkirk@cml.indstate.edu. 
brary staff to learn and develop - she was unfortunately "not certain that as a profession we are doing much better in addressing staff development either on a daily basis in specific skills training or regarding major institutional change." ${ }^{3}$

\section{The first step in moving libraries toward where they need to be in terms of their provision of staff training on information technology is to learn what the current training practices are.}

The first step in planning any successful staff development or training program is to conduct a needs assessment to determine the knowledge and skill level of the staff. Only after this assessment has been completed can the training needed to move staff from their current level of knowledge and skills to the desired level be determined. Similarly, the first step in moving libraries toward where they need to be in terms of their provision of staff training on information technology is to learn what the current training practices are. The purpose of this study was to survey academic libraries in the state of Minnesota within the newly formed MnSCU system to find out what these libraries are doing to train their staff on information technology. The survey attempted to answer the following questions:

1. On which types of technology have staff received training?

2. Who has received training, and have training opportunities and practices been the same for all staff-both librarians and paraprofessionals?

3. What methods have been used to provide training?

\section{Review of the Literature}

How much staff training on information technology is actually taking place in the academic library environment? Although companies in the private sector are often surveyed to determine their training pro- vision for employees, the literature seems to indicate that this type of survey is rarely done in libraries. In 1991, libraries converting to NOTIS were surveyed regarding how they had been affected by the replacement of their automated library systems. The survey concluded that training has grown in significance since the libraries' implementation of the original system; however, this was a measure of the number of staff that had received training rather than a measure of training activities as a whole. ${ }^{4}$

A 1984 survey of Association of Research Libraries (ARL) members on automation training programs for staff members, although more than a decade old, was more to the point. At the time of the survey, only fourteen of the thirty libraries were planning, or already had implemented plans, to provide basic training on the automated system. Of those fourteen libraries, few had performed a formal needs assessment before starting automation training and only one had required training for all library staff members. ${ }^{5}$ It appeared that there have been no similar surveys published recently measuring the amount of training taking place in academic libraries.

Even more inconclusive than the amount of training taking place is information on who is receiving training on information technology, such as whether a difference exists in the training opportunities that professional and paraprofessional staff receive.

\section{Training Methods Used}

The methods used to train library staff on information technology can be determined from both published research and case studies from individual libraries. Suzanne D. Gyeszly and John B. Harer reported in the aforementioned survey of libraries converting to NOTIS that during implementation of the replacement automated system versus implementation of the original system, group instruction and self-taught methods increased by 
400 percent whereas teaching staff members individually grew by only 280 percent. The greatest percentage increase in the use of training tools were, in rank order: (1) in-house training manuals, (2) structured classes, and (3) software programs. However, the most frequently used training tools were, also in rank order: (1) self-instruction, (2) vendor manuals, and (3) in-house training manuals. ${ }^{6}$

Shelley L. Rogers reported on a survey of authority control and database maintenance librarians in 151 major academic and research libraries in the United States and Canada regarding the methods used to train staff in changed technology. The methods used most frequently by these librarians were documentation provided for self-help and workshops, seminars, and classes. The methods the respondents reported that their supervisors used most frequently to receive training were workshops, seminars, and classes. The respondents reported that the method used most often by the staff they supervised were small-group training sessions. ${ }^{7}$

Alicia B. Quinn surveyed depository libraries in the state of Texas to determine the methods employed in training library staff members to use federal government CD-ROMs. The fifty-nine depositories surveyed included forty-one academic libraries. The most common methods of training, in rank order, were self-instruction, one-on-one hands-on instruction, and oneon-one instruction using the menu-driven software available on the discs. Less common were "formal training" methods such as workshops and classes. ${ }^{8}$

\section{Types of Technology}

The types of technology that staff are being trained on can be gleaned from the many published case studies of training practice. During the 1980s and early 1990s, these case studies dealt mainly with implementation of automated systems and, later, implementation of replacement systems. Training for online searching also was addressed.
The 1990s have heralded an emphasis on new types of technology, and the recent case studies of training practice concentrate on CD-ROM and the Internet. However, the Internet, a "network of networks," is not a discrete piece of technology like a CD-ROM which can be learned and mastered but, rather, presents quite possibly even more challenges than the most complex automated system. During the development of training programs for

\section{The types of technology that staff are being trained on can be gleaned from the many published case studies of training practice.}

the Internet, some libraries discovered that having an understanding of the Internet, and networks in general, often requires an understanding of more basic computer skills and concepts. Although many libraries neglected to train their staff on these basic skills because it was thought unnecessary for learning automated systems, the lack of understanding in this area is being recognized as a serious gap in knowledge. The Engineering and Science Libraries at MIT discovered this when they began planning Internet training for their staff. Their response was to organize a Continuing Computer Competence program for the library staff. This program consisted of a curriculum of twenty ninety-minute sessions that would provide a foundation of concepts and skills needed for a proper understanding of the Internet. Only after the staff were trained on these basic skills would training on the Internet be addressed. ${ }^{9}$

\section{Conclusion}

Although there are numerous descriptions of successful training programs developed at individual libraries, there is very little published research on how much training of this type is occurring in academic libraries and, specifically, (1) 


\begin{tabular}{|c|c|c|c|c|c|c|c|c|c|c|}
\hline \multicolumn{11}{|c|}{$\begin{array}{c}\text { TABLE } 1 \\
\text { Availability of Training by Technology } \\
\end{array}$} \\
\hline & \multicolumn{2}{|c|}{$\begin{array}{c}\text { All } \\
\text { Technologies }\end{array}$} & \multicolumn{2}{|c|}{$\begin{array}{l}\text { Automated } \\
\text { System }\end{array}$} & \multicolumn{2}{|c|}{ E-mail } & \multicolumn{2}{|c|}{ Internet } & \multicolumn{2}{|c|}{ PCs } \\
\hline & $\mathrm{n}$ & $\%$ & $\mathrm{n}$ & $\%$ & $\mathrm{n}$ & $\%$ & $\mathrm{n}$ & $\%$ & $\mathrm{n}$ & $\%$ \\
\hline $\begin{array}{l}\text { Available to both } \\
\text { professionals and } \\
\text { paraprofessionals }\end{array}$ & 55 & 80.9 & 16 & 94.1 & 14 & 82.3 & 13 & 76.5 & 12 & 70.6 \\
\hline $\begin{array}{l}\text { Available to profes- } \\
\text { sionals only }\end{array}$ & 1 & 1.5 & 0 & 0 & 0 & 0 & 1 & 5.9 & 0 & 0 \\
\hline $\begin{array}{l}\text { Available to paraprofes- } \\
\text { sionals only }\end{array}$ & 0 & 0 & 0 & 0 & 0 & 0 & 0 & 0 & 0 & 0 \\
\hline Not available & 8 & 11.8 & 1 & 5.9 & 1 & 5.9 & 2 & 11.8 & 4 & 23.5 \\
\hline $\begin{array}{l}\text { Technology not } \\
\text { available }\end{array}$ & 4 & 5.9 & 0 & 0 & 2 & 11.8 & 1 & 5.9 & 1 & 5.9 \\
\hline
\end{tabular}

whether any differences exist in the training that professional and paraprofessional staff receive, (2) the methods being used to train staff, and (3) the types of technologies on which staff receive training.

\section{Methodology}

A survey was selected as the best means to find out how academic library staff in the state of Minnesota within the MnSCU system were being trained on information technology.

\section{Development of the Survey Instrument}

Because no survey was found in the literature that sufficiently reflected the scope of this study, an original survey instrument was developed. Ideas for several of the questions came from a survey discussed by Stuart Glogoff and James P. Flynn. ${ }^{10}$

The first set of questions on the survey asked whether training on specific types of technology (i.e., personal computers [PCs], automated systems, e-mail, the Internet) had been made available to library staff and, if so, whether this training was available to professional staff, paraprofessional staff, or both. The second set of questions asked about the methods used to train staff on each type of technology (e.g., in-house workshops, computer-assisted instruction). The third set of questions asked the surveytaker to indicate the frequency with which these methods had been used to train professional and paraprofessional staff on all types of technology. The final set of questions asked for information on the existence of an in-house technology trainer and the position he or she holds.

The survey was pretested at Mankato State University's Memorial Library by the systems librarian. It was revised based on the results of the pretest.

\section{Population Surveyed}

During the summer of 1996, the survey was mailed to systems librarians at twenty-three MnSCU libraries, which include state universities, community colleges, and technical colleges in Minnesota. The libraries surveyed were taken from a list on the MnSCU/PALS automated library network of established MnSCU/PALS sites. The list included the name of the PALS systems librarian at each site. The rationale for surveying this select group of MnSCU libraries was that, being established MnSCU/PALS sites, the libraries included those that would be automated and those that already used technology to some extent. The surveys were 
TABLE 2

Training Methods by Technology

\begin{tabular}{|c|c|c|c|c|c|c|c|c|c|c|}
\hline & \multicolumn{2}{|c|}{$\begin{array}{c}\text { All } \\
\text { Technologies }\end{array}$} & \multicolumn{2}{|c|}{$\begin{array}{c}\text { Automated } \\
\text { System }\end{array}$} & \multicolumn{2}{|r|}{ E-mail } & \multicolumn{2}{|r|}{ Internet } & \multicolumn{2}{|r|}{$\mathrm{PCs}$} \\
\hline & $\mathrm{n}$ & $\%$ (rank) & $\mathrm{n}$ & $\%$ (rank) & $n$ & $\%$ (rank) & $\mathrm{n}$ & $\%$ (rank) & $\mathrm{n}$ & $\%($ rank $)$ \\
\hline $\begin{array}{c}\text { Individual training } \\
\text { by coworker }\end{array}$ & 44 & $64.7(1)$ & 13 & $76.5(1)$ & 10 & $58.8(1)$ & 9 & $52.9(1)$ & 12 & $70.6(1)$ \\
\hline $\begin{array}{l}\text { Individual training } \\
\text { by other individual }\end{array}$ & 33 & $48.5(2)$ & 7 & $41.2(5)$ & 9 & $52.9(2)$ & 8 & $47.1(2)$ & 9 & $52.9(3)$ \\
\hline $\begin{array}{l}\text { Individual training } \\
\text { by supervisor }\end{array}$ & 32 & $47.1(3)$ & 12 & $70.6(2)$ & 6 & $35.3(3)$ & 4 & $23.5(4)$ & 10 & $58.8(2)$ \\
\hline Outside workshops & 32 & $47.1(3)$ & 10 & $58.8(3)$ & 5 & $29.4(4)$ & 7 & $41.2(3)$ & 10 & $58.8(2)$ \\
\hline In-house workshops & 30 & $44.1(4)$ & 5 & $29.4(6)$ & 9 & $52.9(2)$ & 7 & $41.2(3)$ & 9 & $52.9(3)$ \\
\hline Vendor workshops & 13 & $19.1(5)$ & 9 & $52.9(4)$ & 1 & $5.9(7)$ & 1 & $5.9(7)$ & 2 & $11.8(6)$ \\
\hline Formal coursework & 13 & $19.1(5)$ & 1 & $5.9(8)$ & 3 & $17.6(5)$ & 4 & $23.5(4)$ & 5 & $29.4(4)$ \\
\hline E-mail workshops & 9 & $13.2(6)$ & 1 & $5.9(8)$ & 2 & $11.8(6)$ & 3 & $17.6(5)$ & 3 & $17.6(5)$ \\
\hline CAI & 6 & $8.9(7)$ & 2 & $11.8(7)$ & 1 & $5.9(7)$ & 1 & $5.9(7)$ & 2 & $11.8(6)$ \\
\hline No training available & 4 & 5.9 & 0 & 0 & 1 & 5.9 & 2 & 11.8 & 1 & 5.9 \\
\hline $\begin{array}{l}\text { Technology not } \\
\text { available }\end{array}$ & 1 & 1.5 & 0 & 0 & 1 & 5.9 & 0 & 0 & 0 & 0 \\
\hline
\end{tabular}

addressed to the PALS systems librarian at each library because systems librarians often assume responsibility for either providing training on technology for other library staff or ensuring that such training is made available.

The first mailing of the surveys took place in July 1996, with a follow-up mailing in August. The response rate was 73.9 percent.

\section{Presentation and Analysis of Data}

The seventeen libraries that returned surveys ranged in size from two FTEs to thirty-six FTEs and included libraries from state universities, community colleges, and technical colleges.

\section{Availability of Training for Different Types of Technology}

As mentioned earlier, the first set of questions was designed to find out whether training was available to the library staff members on major types of technology (i.e., PCs, automated systems, e-mail, and the Internet) and whether there was any difference in the availability of training for professionals and paraprofessionals. In 80.9 percent of the libraries surveyed, training was available to both professionals and paraprofessionals on all types of technology. In a small percentage of libraries, PCs, e-mail, and the Internet were unavailable (see table 1).

In 80.9 percent of the libraries surveyed, training was available to both professionals and paraprofessionals on all types of technology.

The availability of training was highest on automation, with 94.1 percent of the libraries receiving automation training. Training on e-mail and the Internet was available to all staff members in 82.3 and 76.5 percent of the libraries, respectively; training on PCs was available to only 70.6 percent of the libraries. The discovery that many of the library staff members have not received training on using PCs agrees with the findings in the literature that library staff lack basic computer competence. ${ }^{11}$ 
In general, both professionals and paraprofessionals had equal access to training. Where training was available, it was usually available to both groups. The only difference was that 5.9 percent of the libraries offered Internet training to professionals only. The 5.9 percent represents one library, and a note on the survey indicated that Internet access was available to professional librarians only.

\section{Training Methods for Different Types of Technology}

The next set of questions gave a list of training methods (e.g., individual training by supervisor, vendor workshops) for each type of technology and asked respondents to mark all the methods that had been used to train at least one staff member at some time. Table 2 lists these results in terms of percentage of libraries using the particular method at least once. (A response of 100 percent would indicate that all the libraries had used the training method at least once.) It should be noted that the number of libraries reporting that the technology was unavailable or that no training was available does not match the figures reported in the first set of questions. One theory as to why these differences exist is that when the respondents saw the list of training methods in the second set of questions, they were prompted to remember that there had been some type of training available.

\section{The percentage of libraries that made PC training available was substantially lower than that of libraries that offered training on the other technologies.}

For all types of technology, individualized instruction by a coworker was the most common training method used $(64.7 \%)$. This method was very common for training on an automated system, used in 76.5 percent of the libraries sur- veyed. Individualized training by an individual other than a supervisor or coworker $(48.5 \%)$ was the next most common training method used. For training on e-mail, the Internet, and PCs, this "other individual" was, in most cases, a member of the computing center staff. For training on an automated system, this individual was usually a vendor from that system (i.e., PALS system staff). However, for automated system training, this method was used in only 41.2 percent of libraries, compared to several other methods that were used more often, including individualized training by a supervisor $(70.6 \%)$, outside workshops $(58.8 \%)$, and vendor workshops $(52.9 \%)$. The third most common type of training for all technologies was individualized training by a supervisor, which was used in 47.1 percent of all libraries, especially for training on automated systems, as mentioned above.

Workshops also were a method that libraries commonly used for training. These included workshops conducted outside the library $(47.1 \%)$, in-house workshops (44.1\%), and workshops conducted by a vendor (19.1\%). Vendor-conducted workshops were a common method used to provide training on an automated system $(52.9 \%)$; however, this method was not as commonly used for any other technology. On the other hand, libraries commonly used in-house workshops for e-mail training $(52.9 \%)$, PCs $(52.9 \%)$, and the Internet $(41.2 \%)$, but not for training on an automated system (29.4\%).

Training methods such as e-mail workshops conducted over the Internet and computer-assisted instruction (CAI) were less commonly used $(13.2 \%$ and $8.9 \%$, respectively). E-mail workshops were used most often for PC or Internet training (17.6\% for each), and CAI was used most often for training on PCs and automated systems (11.8\% for each).

\section{Training Methods Used Most Frequently}

The next set of questions asked respondents to indicate the three methods of 


\begin{tabular}{|c|c|c|c|c|c|c|}
\hline \multicolumn{7}{|c|}{$\begin{array}{c}\text { TABLE } 3 \\
\text { Training Methods Used Most Frequently by } \\
\text { Professionals and Paraprofessionals } \\
\end{array}$} \\
\hline & \multicolumn{2}{|c|}{$\begin{array}{l}\text { All Staff } \\
\text { Members }\end{array}$} & \multicolumn{2}{|c|}{ Professionals } & \multicolumn{2}{|c|}{ Paraprofessionals } \\
\hline & $\mathrm{n}$ & $\% \quad($ rank $)$ & $\mathrm{n}$ & $\%$ (rank) & $\mathrm{n}$ & $\% \quad$ (rank) \\
\hline $\begin{array}{l}\text { Individualized training by } \\
\text { coworker }\end{array}$ & 56 & $54.9 \quad(1)$ & 30 & 58.8 & 26 & 51.0 \\
\hline In-house workshops & 36 & $35.3 \quad(2)$ & 18 & $35.3 \quad(2)$ & 18 & $35.3 \quad(3)$ \\
\hline $\begin{array}{l}\text { Individualized training by } \\
\text { supervisor }\end{array}$ & 32 & 31.4 & 7 & $13.7 \quad(5)$ & 25 & $49.0 \quad(2)$ \\
\hline $\begin{array}{l}\text { Individualized training by } \\
\text { other }\end{array}$ & 29 & 28.5 & 16 & $31.4 \quad(3)$ & 13 & 25.5 \\
\hline Outside workshops & 26 & $25.5 \quad(5)$ & 14 & 27.5 & 12 & $23.5(5)$ \\
\hline Vendor workshops & 12 & $11.8 \quad(6)$ & 7 & $13.7 \quad(5)$ & 5 & 9.8 (6) \\
\hline E-mail workshops & 10 & $9.8 \quad(7)$ & 6 & $11.8 \quad(6)$ & 4 & 7.8 (7) \\
\hline Formal coursework & 3 & $3.0 \quad(8)$ & 3 & $5.9(7)$ & 0 & $0 \quad(9)$ \\
\hline CAI & 2 & $2.0 \quad(9)$ & 1 & $2.0 \quad(8)$ & 1 & $2.0 \quad(8)$ \\
\hline
\end{tabular}

training used most frequently by professionals and paraprofessionals. The most frequent method was ranked as 1 , the second most-frequent method as 2 , and the third as 3 . In coding these results, a 1 was assigned a value of 3 , a 2 a value of 2 , and a 3 a value of 1 . A particular method that was rated by all libraries as 1 (i.e., used most frequently as a training method) received a score of 100 percent. The results can be found in table 3 .

The most frequently used training methods for both professionals and paraprofessionals were, in rank order, individualized training by a coworker (54.9\%), in-house workshops (35.3\%), and individualized training by a supervisor (31.4\%). The methods used most frequently by paraprofessionals coincided with these results, except that individualized training by a supervisor was used more often as a training method (49\%) than in-house workshops (35.3\%). The training methods used by professionals differed slightly. Although the methods used most frequently, in order, also were individualized training by a coworker (58.8\%) and in-house workshops (35.3\%), the method used third most frequently was individualized training by an individual other than a supervisor or coworker (31.4\%). Where training by supervisors is a method used frequently to train paraprofessionals, it is used much less frequently to train professionals (13.7\%). The other results were roughly the same for both professionals and paraprofessionals.

\section{In-House Trainers}

When asked if there was an in-house trainer who regularly provided training to library staff members other than those he or she supervises, 94.1 percent of the libraries indicated that there was none. Only one of the libraries (5.9\%) had an inhouse trainer. The question also asked respondents to indicate the position of this person. This single in-house trainer was a graduate assistant working at the library and not a permanent library staff member.

\section{Conclusions}

In the majority of the libraries surveyed training was available on PCs, automated systems, e-mail, and the Internet. However, the percentage of libraries that made PC training available was substantially lower than that of libraries that offered training on the other technologies. This agrees with findings in the 
literature that gaps exist in the area of basic computer competence.

Although a variety of training methods was used, the most frequently used methods for both professional and paraprofessional staff were individualized training and workshops. Methods such as CAI and e-mail workshops were used substantially less often. In addition, an in-house trainer was found in only one library.

Finally, the survey results indicated that there were no substantial differences in the types of training that professional and paraprofessional staff received, in either the availability of training or the type of training method used.

\section{Implications}

One of the most important findings of the survey was that, within these libraries, many staff have not received training in basic computer competence - that is, staff members lack basic training on how to operate their PCs. What this often means is that some of the necessary building blocks on which further training tries to build are missing, and the training is therefore not as successful as it could be. The MnSCU libraries surveyed seem to be in the same position as other libraries discussed in the literature.

With regard to the other findings, the numbers seem to indicate that library staff members within the MnSCU libraries are, for the most part, receiving training on the various technologies. However, what is not clear are the qualitative aspects of this training. For example, these findings do not show whether there was enough training provided or whether the training provided was successful. The limitations of this study prevent these questions from being answered.

\section{Recommendations}

To receive the whole picture of where the library staff within the MnSCU system are with regard to their training needs, it is recommended that a personal skills assessment be given as a follow-up to this core study. The assessment could be given to a sample of staff in each library to evaluate their skill levels on each of the individual technologies. Another method of gaining this information is to interview the systems librarian at each library to learn his or her view of the collective skill levels of the staff members on each of the technologies.

\section{Suggestions for Further Research}

This research study on training provision in libraries within the MnSCU system, including the follow-up study suggested above, could be conducted in a different population of libraries. It also could be done among a sample of academic libraries within the United States. With more information on what libraries are doing to train their staff on information technology, an action plan could be developed by the library profession as a whole as well as by individual libraries who may be falling short on this essential practice.

\section{Notes}

1. Roy Tennant, "The Virtual Library Foundation: Staff Training and Support," Information Technology and Libraries 14 (Mar. 1995): 46-49.

2. Sheila D. Creth, "Staff Development: Where Do We Go from Here?" Library Administration \& Management 4 (summer 1990): 131.

3. Ibid.

4. Suzanne D. Gyeszly and John B. Harer, "Replacement of Automated Systems: Organizational and Staff Training Considerations," Journal of Library Administration 14, no. 1 (1991): 87-105.

5. Tom Wilding, Staff Training for Automation in ARL Libraries, SPEC Kit no. 109 (Washington, D.C.: ARL, 1984).

6. Gyeszly and Harer, "Replacement of Automated Systems," 87-105.

7. Shelley L. Rogers, "Automation Change: A Survey of Authority Control/Database Maintenance Librarians," Library \& Information Science Research 14 (July-Sept. 1992): 281-98. 
8. Alicia B. Quinn, "Methods for Training Library Staff Members in the Use of CD-ROMs in Federal Depository Libraries in Texas: A Survey," Journal of Government Information 23 (Mar./ Apr. 1996): 151-59.

9. Margret Lippert, "Continuing Computer Competence: A Training Program for the '90s," Bulletin of the American Society for Information Science 20 (Feb./Mar. 1994): 18-19.

10. Stuart Glogoff and James P. Flynn, "Developing a Systematic In-house Training Program for Integrated Library Systems," College E Research Libraries 48 (Nov. 1987): 528-36.

11. Lippert, "Continuing Computer Competence," 18-19. 